NASA/CR-2004-212980

\title{
Laser-Induced Breakdown Spectroscopy of Trace Metals
}

Randall L. Vander Wal

National Center for Microgravity Research, Cleveland, Ohio

Thomas M. Ticich and Joseph R. West, Jr.

Centenary College, Shreveport, Louisiana 
Since its founding, NASA has been dedicated to the advancement of aeronautics and space science. The NASA Scientific and Technical Information (STI) Program Office plays a key part in helping NASA maintain this important role.

The NASA STI Program Office is operated by Langley Research Center, the Lead Center for NASA's scientific and technical information. The NASA STI Program Office provides access to the NASA STI Database, the largest collection of aeronautical and space science STI in the world. The Program Office is also NASA's institutional mechanism for disseminating the results of its research and development activities. These results are published by NASA in the NASA STI Report Series, which includes the following report types:

- $\quad$ TECHNICAL PUBLICATION. Reports of completed research or a major significant phase of research that present the results of NASA programs and include extensive data or theoretical analysis. Includes compilations of significant scientific and technical data and information deemed to be of continuing reference value. NASA's counterpart of peerreviewed formal professional papers but has less stringent limitations on manuscript length and extent of graphic presentations.

- TECHNICAL MEMORANDUM. Scientific and technical findings that are preliminary or of specialized interest, e.g., quick release reports, working papers, and bibliographies that contain minimal annotation. Does not contain extensive analysis.

- CONTRACTOR REPORT. Scientific and technical findings by NASA-sponsored contractors and grantees.
- CONFERENCE PUBLICATION. Collected papers from scientific and technical conferences, symposia, seminars, or other meetings sponsored or cosponsored by NASA.

- SPECIAL PUBLICATION. Scientific, technical, or historical information from NASA programs, projects, and missions, often concerned with subjects having substantial public interest.

- TECHNICAL TRANSLATION. Englishlanguage translations of foreign scientific and technical material pertinent to NASA's mission.

Specialized services that complement the STI Program Office's diverse offerings include creating custom thesauri, building customized databases, organizing and publishing research results ... even providing videos.

For more information about the NASA STI Program Office, see the following:

- Access the NASA STI Program Home Page at http://www.sti.nasa.gov

- E-mail your question via the Internet to help@sti.nasa.gov

- Fax your question to the NASA Access Help Desk at 301-621-0134

- Telephone the NASA Access Help Desk at 301-621-0390

- Write to:

NASA Access Help Desk

NASA Center for AeroSpace Information 7121 Standard Drive

Hanover, MD 21076 
NASA/CR-2004-212980

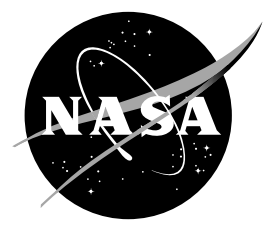

\section{Laser-Induced Breakdown Spectroscopy of Trace Metals}

Randall L. Vander Wal

National Center for Microgravity Research, Cleveland, Ohio

Thomas M. Ticich and Joseph R. West, Jr.

Centenary College, Shreveport, Louisiana

Prepared under Cooperative Agreement NAC3-544

National Aeronautics and

Space Administration

Glenn Research Center 


This report contains preliminary
findings, subject to revision as
analysis proceeds.

Available from

NASA Center for Aerospace Information 7121 Standard Drive

Hanover, MD 21076
National Technical Information Service 5285 Port Royal Road Springfield, VA 22100

Available electronically at http://gltrs.grc.nasa.gov 


\title{
Laser-Induced Breakdown Spectroscopy of Trace Metals
}

\author{
Randall L. Vander Wal* \\ National Center for Microgravity Research \\ Cleveland, Ohio 44135 \\ Thomas M. Ticich and Joseph R. West, Jr. \\ Centenary College \\ Shreveport, Louisiana 71134
}

\section{Summary}

An alternative approach for laser-induced breakdown spectroscopy (LIBS) determination of trace metal determination in liquids is demonstrated. The limits of detection (LOD) for the technique ranged from 10 ppb to 10 ppm for 15 metals (Mg, Al, Si, Ca, Ti, Cr, Fe, Co, Ni, Cu, Zn, As, Cd, Hg, Pb) tested.

\section{Introduction}

The detection and quantification of light elements and heavy metals within liquid samples and those produced by acid dissolution of solids are pertinent to industrial processing, environmental monitoring and waste treatment (refs. 1 to 5). To-date, laser-induced breakdown spectroscopy (LIBS) has been tested with limited success. Dissolved gases, particulate material and nucleation-induced bubbles produced by prior laser pulses can lead to misfocusing of the laser beam and can also serve as breakdown sites prior to the laser beam focus (refs. 1 to 3, 6, and 7). Additionally, the high local density within the liquid leads to rapid quenching which prohibits temporally selective detection, high collision rates which broaden spectral transitions and confines the plasma emission spatially rendering spatially selective detection problematic. Given these inherent difficulties, in situ LIBS analysis of liquids has not been widely successful with detection limits in the range of 1 to $100 \mathrm{ppm}$ for light metals (refs. 1, 3 to 6, and 8 to 11). As a result, even fewer studies have investigated detection of heavy metals (refs. 1 to 3 and 6) with $\mathrm{Hg}$ being reported undetectable at 1000 ppm (ref. 3).

In contrast, solid surface analysis via LIBS exploits the strengths of the technique without the problems inherent to liquid analysis. Solid surfaces provide a uniform, well-defined sample surface. Additionally, the ambient background gas and pressure can be tailored to govern the plasma spatial and temporal evolution thereby optimizing detection conditions (refs. 12 to 16). Finally, surface analysis of a reproducible uniform material avoids the inherent difficulties associated with varying sample matrices, particle grain size effects, analyte dispersion uniformity and varying moisture content (refs. 17 and 18). In the work presented here, trace elemental identification within solutions is transformed into a solid surface analysis. Measurements for 15 metals (Mg, Al, Si, Ca, Ti, Cr, Fe, Co, Ni, Cu, Zn, As, Cd, Hg, Pb) are presented.

\footnotetext{
*Phone: 216-433-9065; Fax: 216-433-3793; E-mail: randy@rvander.grc.nasa.gov
} 


\section{Experimental Approach}

Our approach consisted of evaporation of the analyte solution upon an amorphous graphite substrate followed by LIBS analysis of the substrate surface. Using calibrated pipets, aliquots of environmental standard solutions (commercially available solutions of the metal as a nitrate or chloride salt in roughly 2 percent $\mathrm{HNO} 3$ or $\mathrm{HCl}$, respectively) or diluted solutions prepared from these certified standards were deposited upon the carbon disks and then evaporated to dryness.

A pulsed Nd:YAG laser provided light at $1064 \mathrm{~nm}$ for the LIBS analysis with the same single laser pulse serving to both atomize and electronically excite the elements. Using a $300 \mathrm{~mm}$ focal length fused silica lens, the beam focus was placed approximately $1 \mathrm{~cm}$ behind the sample surface. The beam diameter on the graphite planchet was determined to be roughly $750 \mu \mathrm{m}$, resulting in a laser fluence of roughly $35 \mathrm{~J} / \mathrm{cm}^{2}$ and an intensity of $4.4 \mathrm{GW} / \mathrm{cm}^{2}$ for a nominal $8 \mathrm{nsec}$ pulse width.

LIBS emission from the expanding plasma plume was directed into a 1-meter fused silica optical fiber using a collimating beam probe. A 1/4 meter spectrograph fitted with a cooled intensified array camera generated the spectra for subsequent analysis. For low resolution survey spectra, a 147 groove/mm grating blazed at $300 \mathrm{~nm}$ was used while a 1200 groove $/ \mathrm{mm}$ grating blazed at $300 \mathrm{~nm}$ provided sufficient spectral resolution for detailed analysis of the atomic and ionic emission.

Results from previous LIBS investigations exploring the effects of focussing. Laser excitation wavelength and laser repetition rate were used to select the conditions used here. Extensive testing of LIBS detection in different buffer gases and pressures confirmed results of prior LIBS investigations (refs. 12 to 16) and led to the choice of 75 Torr Ar.

\section{Results}

\section{Substrate Characterization}

Figure 1 shows low resolution LIBS spectra from an undoped carbon disk. With the exception of the carbon atomic emission lines at 193.3 and 247.8 corresponding to $\mathrm{C}$ atom transitions from the ${ }^{1} \mathrm{P}_{0}$ level to the ${ }^{1} \mathrm{D}$ and ${ }^{1} \mathrm{~S}$ levels, respectively, the ultraviolet region is free of substrate spectral emissions.

\section{Analyte Spectral Transition Selection and Identification}

Table I lists the spectral transitions associated with LIBS in this study for all 15 metals tested under higher resolution. In some cases, such as for $\mathrm{Hg}$, multiple spectral regions were investigated. At higher resolution. The spectral transitions chosen for analysis possess a strong oscillator strength, a moderately low excited-state energy level, and a minimal of overlap with spectral emissions from other elements. Figure 2 illustrates some representative spectra for selected elements.

\section{Linearity and Limits of Detection}

To assess the analytical capability of our technique, we explored the linearity with analyte concentration and determined limits of detection. Analytical working curves were developed over a range of concentrations for $\mathrm{As}, \mathrm{Cd}, \mathrm{Hg}, \mathrm{Pb}$, and $\mathrm{Cr}$. Figure 3 shows the results for $\mathrm{As}$, $\mathrm{Cr}$, and $\mathrm{Pb}$. Identical results were obtained using either the peak or spectrally-integrated intensities of elemental emissions. 
Given limited success with developing analytical working curves, an empirical approach was undertaken to determine limits of detection (LOD). In our approach, the LOD was assigned to the concentration that resulted in recognizable elemental emission $(S / N>3)$ in greater than 75 percent of the spectra of a series of single laser pulse LIBS spectra. Table 1 also lists the detection limits of the elements determined in this manner.

Although the limit of detection is revealing, it does not convey the minute aliquots that could be analyzed by the technique in screening for trace elements. The laser pulse, with a spot size of $0.075 \mathrm{~cm}$, samples 0.13 percent of the analyte in the $1.0 \mathrm{ml}$ liquid volume initially deposited. This calculation assumes that the deposited liquid uniformly covers an area $3.5 \mathrm{~cm}^{2}$ and that the evaporation resulted in uniform deposition over the carbon planchet. The liquid was not deposited to the edge of the planchet to avoid loss of material by runoff. For an initial liquid concentration of $0.1 \mathrm{ppm}$, this corresponds to $130 \mathrm{pg}$ of trace metal sampled. For iron, this corresponds to approximately 2 picomoles of material. This calculated amount is competitive with those routinely reported using laser-induced fluorescence and graphite furnace atomic absorption spectroscopy. Another unique feature of the technique is the small volumes required. Taking the volume of the liquid cylinder with base equal to the laser spot size and height equal to the initially deposited liquid height, a single laser pulse samples a volume of 1.3 microliters. This calculated value is competitive with those routinely reported using laser-induced fluorescence and graphite furnace atomic absorption spectroscopy. Clearly, LIBS applied using our approach has potential for trace-element detection.

\section{References}

1. D.A. Cremers, L.J. Radziemski, and T.R. Loree, Appl. Spectrosc. 38:721 (1984).

2. J.R. Wachter and D.A. Cremers, Appl. Spectrosc. 41:1042 (1987).

3. R. Knoop, F.J. Scherbaum, and J.O. Kim, Fresenius J. Anal. Chem. 355:16 (1996).

4. G. Arca, A. Ciucci, V. Palleschi, S. Rastelli, and E. Tognoni, Appl. Spectrosc. 51:1102 (1997).

5. L.M. Berman and P.J. Wolf, Appl. Spectrosc. 52:438 (1998).

6. W.F. Ho, C.W. Ng, and N.H. Cheung, Appl. Spectrosc. 51:87 (1997).

7. A.V. Buntenin and B.Ya. Kogan, Kvantovaya Elektron. 1:143 (1971), Sov. J. Quantum Electron. 1:561 (1972).

8. D.Yu. Tsipenyuk, D.V. Vlasov, A.M. Prokhorov, and P.I. Ivashkin, Laser Physics 3:910 (1993).

9. H.A. Archontaki and S.R. Crouch, Appl. Spectrosc. 42:741 (1988).

10. K.C. Ng, N.L. Ayala, J.B. Simeonsson, and J.D. Winefordner, Analytica Chim. Acta 269:123 (1992).

11. D.E. Poulain and D.R. Alexander, Appl. Spectrosc. 49:569 (1995).

12. D.A. Rusak, B.C. Castle, B.W. Smith, and J.D. Winefordner, Crit. Rev. Anal. Chem. 27:257 (1997).

13. V. Majidi and M.R. Joseph, Crit. Rev. Anal. Chem. 23:143 (1992).

14. Y. Iida, Appl. Spectrosc. 43:229 (1989).

15. X.L. Mao, M.A. Shannon, A.J. Fernandez, and R.E. Russo, Appl. Spectrosc. 49:1054 (1995).

16. Y.-I. Lee, K. Song, H.-K. Cha, J.-M. Lee, M.-C. Park, G.-H. Lee, and J. Sneddon, Appl. Spectrosc. 51:959 (1997).

17. R. Wisbrun, I. Schechter, R. Niessner, H. Schroder, and K.L. Kompa, Anal. Chem. 66:2964 (1994).

18. K.Y.Yamamoto, D.A. Cremers, M.J. Ferris, and L.E. Foster, Appl. Spectrosc. 50:222 (1996). 
TABLE I.-LIMITS OF DETECTION FOR THIS STUDY AND COMPARISON WITH OTHER RESULTS.

\begin{tabular}{|c|c|c|c|}
\hline \multirow[t]{2}{*}{ Element } & \multicolumn{2}{|r|}{ This study } & Other work \\
\hline & $\begin{array}{c}\text { LOD, } \\
\text { ppm }\end{array}$ & Spectral transitions, ${ }^{\mathrm{a}, \mathrm{b}} \mathrm{nm}$ & $\begin{array}{c}\text { LOD, } \\
\text { ppm }\end{array}$ \\
\hline $\mathrm{Mg}$ & 0.01 & $279.55,280.27$ & ${ }^{\mathrm{a}} 3,{ }^{\mathrm{b}} 9,{ }^{\mathrm{c}} 100,{ }^{\mathrm{d}} 1.9$ \\
\hline $\mathrm{Al}$ & 0.01 & $394.4,396.15$ & ${ }^{\mathrm{a}} 3,{ }^{\mathrm{c}} 20,{ }^{\mathrm{d}} 5.2$ \\
\hline $\mathrm{Si}$ & 0.01 & $288.16,251-253$ & \\
\hline $\mathrm{Ca}$ & 0.01 & 393.37, 396.85 & ${ }^{\mathrm{c}} 8,{ }^{\mathrm{g}} 0.3,{ }^{\mathrm{h}} 0.13,{ }^{\mathrm{d}} 25,{ }^{\mathrm{e}} 0.8,{ }^{\mathrm{f}} 0.4$ \\
\hline $\mathrm{Ti}$ & 0.1 & 323.4, 334-339 & \\
\hline $\mathrm{Cr}$ & 0.1 & 266-268, 274-279, 283-288 & ${ }^{\mathrm{d}} 0.1$ \\
\hline $\mathrm{Fe}$ & 0.01 & 238-241, 260-263 273-276 & $g_{7.5}$ \\
\hline $\mathrm{Co}$ & $>0.1$ & 238-242, 340-348, 349-353 & \\
\hline $\mathrm{Ni}$ & 0.01 & 221-223, 229-231 & i 36.4 \\
\hline $\mathrm{Cu}$ & 0.01 & $324.75,327.4$ & \\
\hline $\mathrm{Zn}$ & 1.0 & $330.26,330.29,334.5,334.56$ & \\
\hline As & 5 & $274.5,278.02,286.04$ & \\
\hline \multirow[t]{2}{*}{$\mathrm{Cd}$} & 1.0 & 214.44 & $\mathrm{~h}_{500}$ \\
\hline & 0.1 & $226.5,228.5$ & \\
\hline $\mathrm{Hg}$ & 10 & 253.65 & undetectable at $1000 \mathrm{ppm}$ \\
\hline \multirow[t]{2}{*}{$\mathrm{Pb}$} & 2 & 261.37, 261.42, 280.2, 283.31 & ${ }^{\mathrm{h}} 12.5$ \\
\hline & 10 & $405.78,406.21$ & \\
\hline
\end{tabular}

${ }^{\mathrm{a}}$ Multiple wavelengths correspond to transitions of similar intensity in the LIBS spectra which proved equally useful in determining detection limits.

${ }^{b}$ Where wavelength ranges are listed, multiple transitions are present and were not fully resolved with our spectral resolution.

${ }^{\mathrm{c}} \mathrm{Ng}$ et al., ref. 6 (liquid aerosol).

${ }^{\mathrm{d}}$ Arca et al., ref. 4 (liquid surface).

${ }^{\mathrm{e}}$ Cremers et al., ref. 1 (solution).

${ }^{\mathrm{f}}$ Archontaki et al., ref. 9 (droplet).

${ }^{\mathrm{g}} \mathrm{Yu}$ et al., ref. 8 (liquid surface).

${ }^{\mathrm{h}}$ Knopp et al., ref. 3 (solution).

${ }^{\mathrm{i} B e r m a n}$ et al., ref. 5 (liquid surface). 


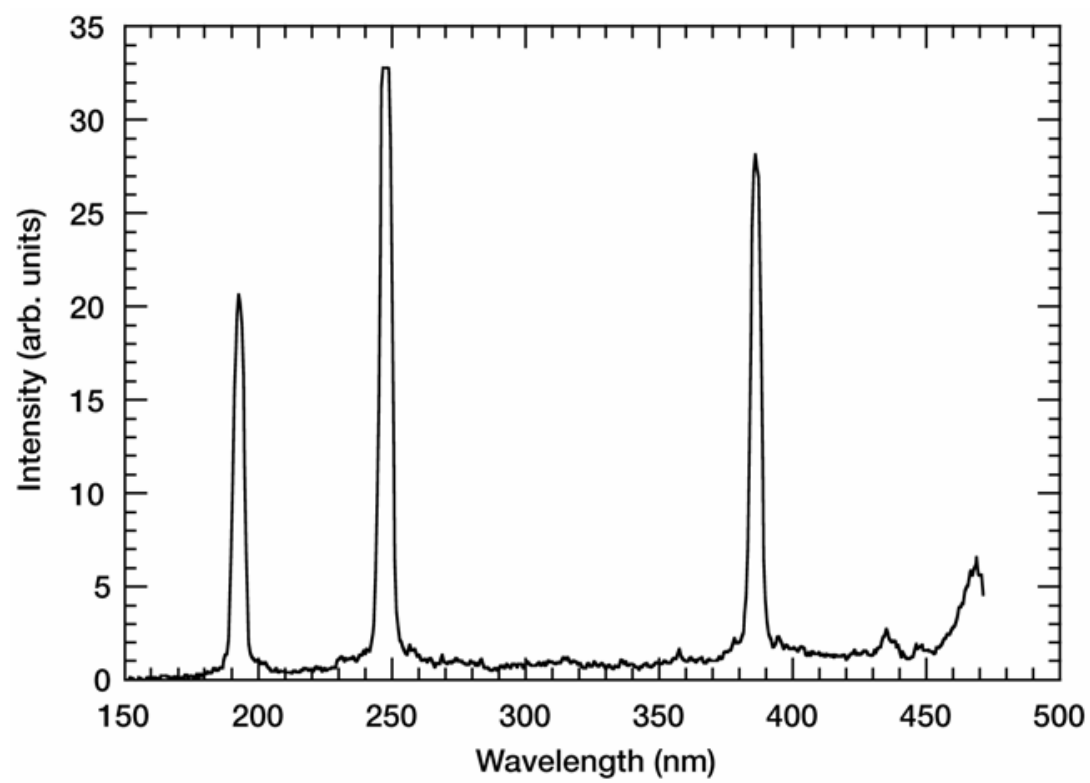

Figure 1.-LBIS spectrum for an undoped carbon disk in 740 Torr Helium from 150-470 nm. The excitation laser fluence to generate in the spectra was $225 \mathrm{~J} / \mathrm{cm}^{2}$. The emission was detected at a time delay of $5 \mu \mathrm{s}$ and integrated over a $0.1 \mu$ s gate. 

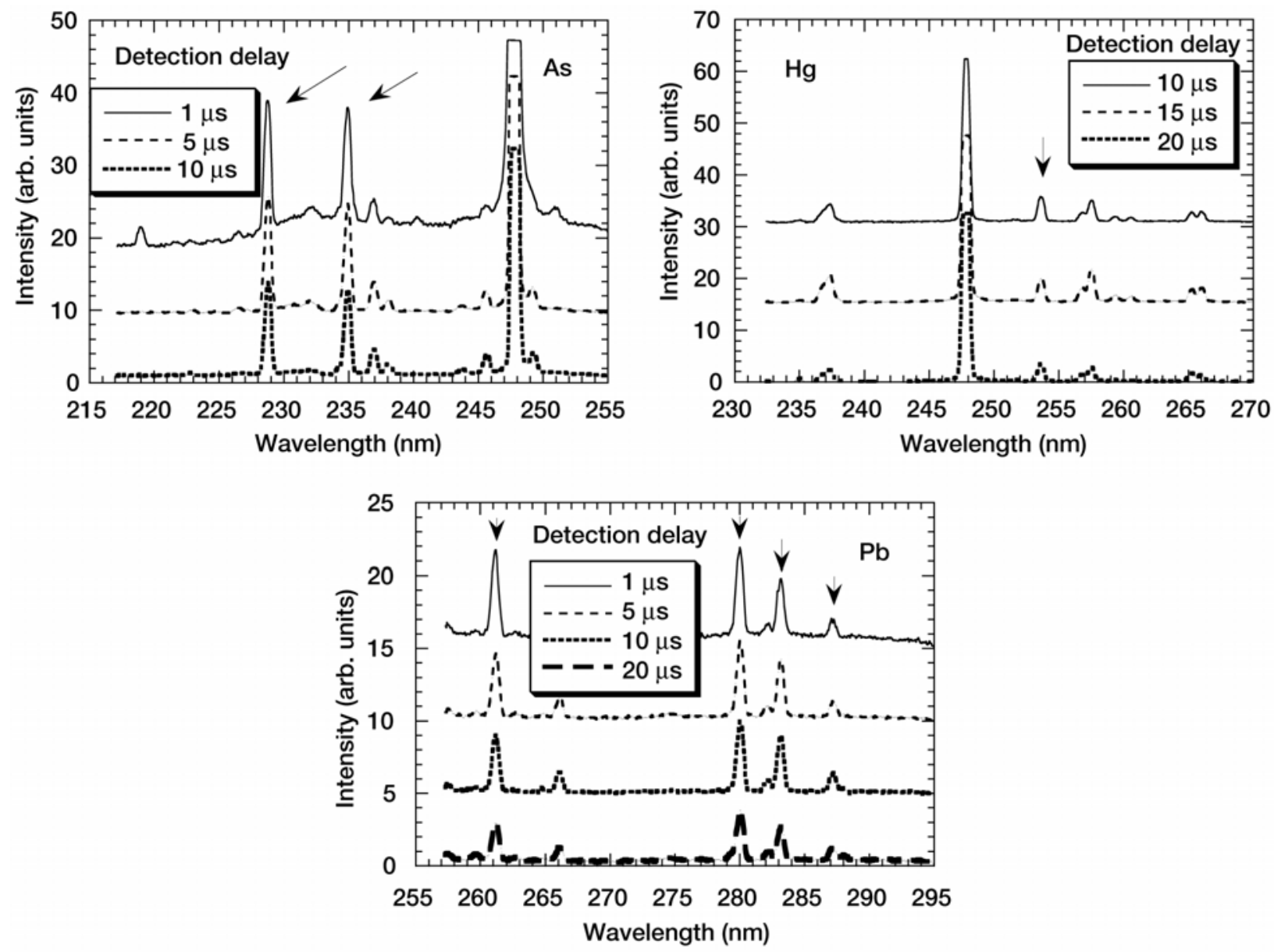

Figure 2.-High resolution LIBS spectra for $\mathrm{As}, \mathrm{Hg}$ and $\mathrm{Pb}$ using a $1 \mu$ s gate with various delay times to monitor the emission. Arrows in the spectra indicate emission from the element of interest. The concentration of each metal in the deposited solution was $1000 \mathrm{ppm}$. For each spectrum, the signal was integrated over a $1 \mu \mathrm{s}$ gate. 

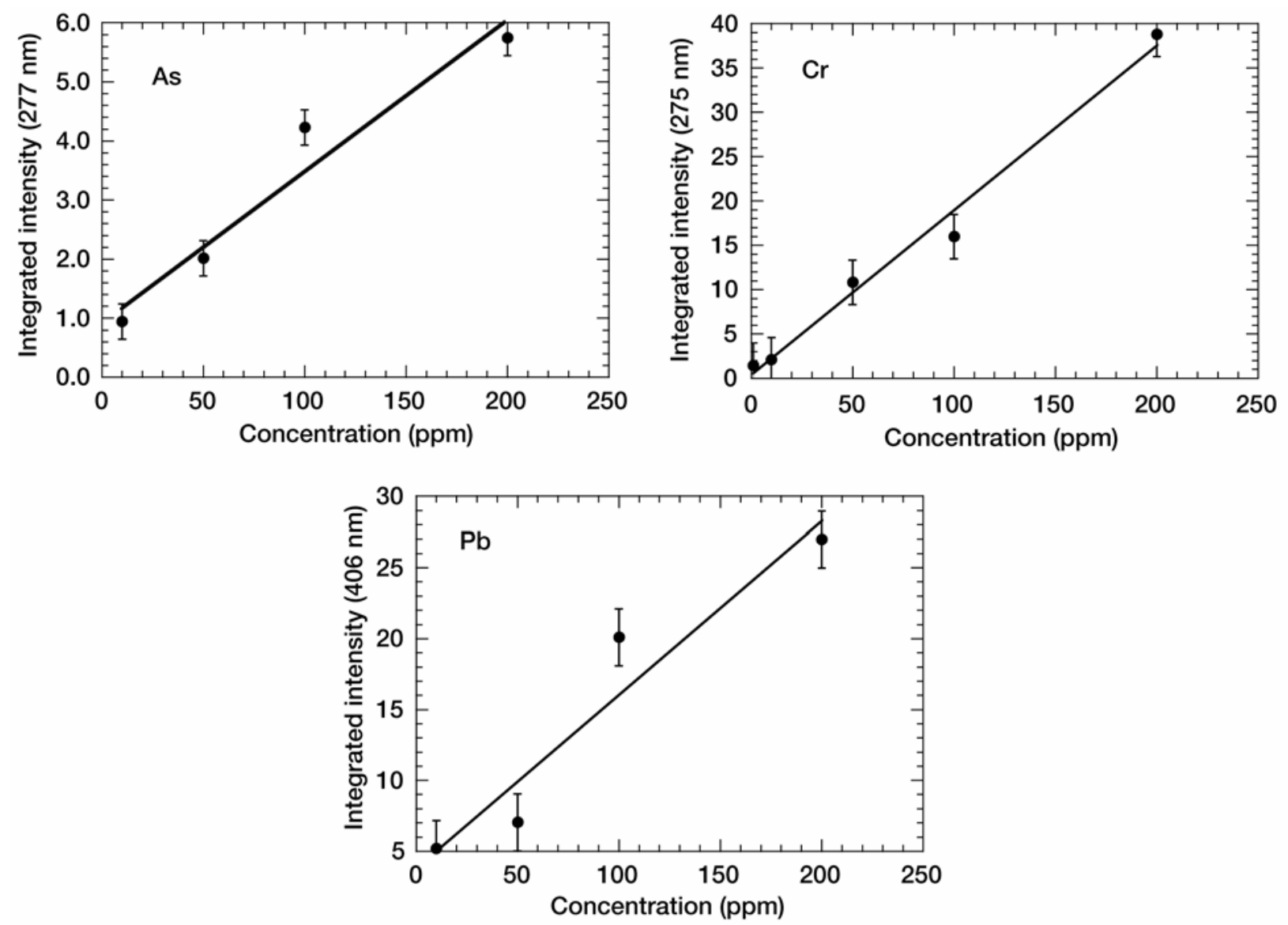

Figure 3.-Analytical working curves based on the integrated elemental emission from LIBS spectral transitions as a function of concentration for the elements $\mathrm{As}, \mathrm{Cr}$, and $\mathrm{Pb}$. 


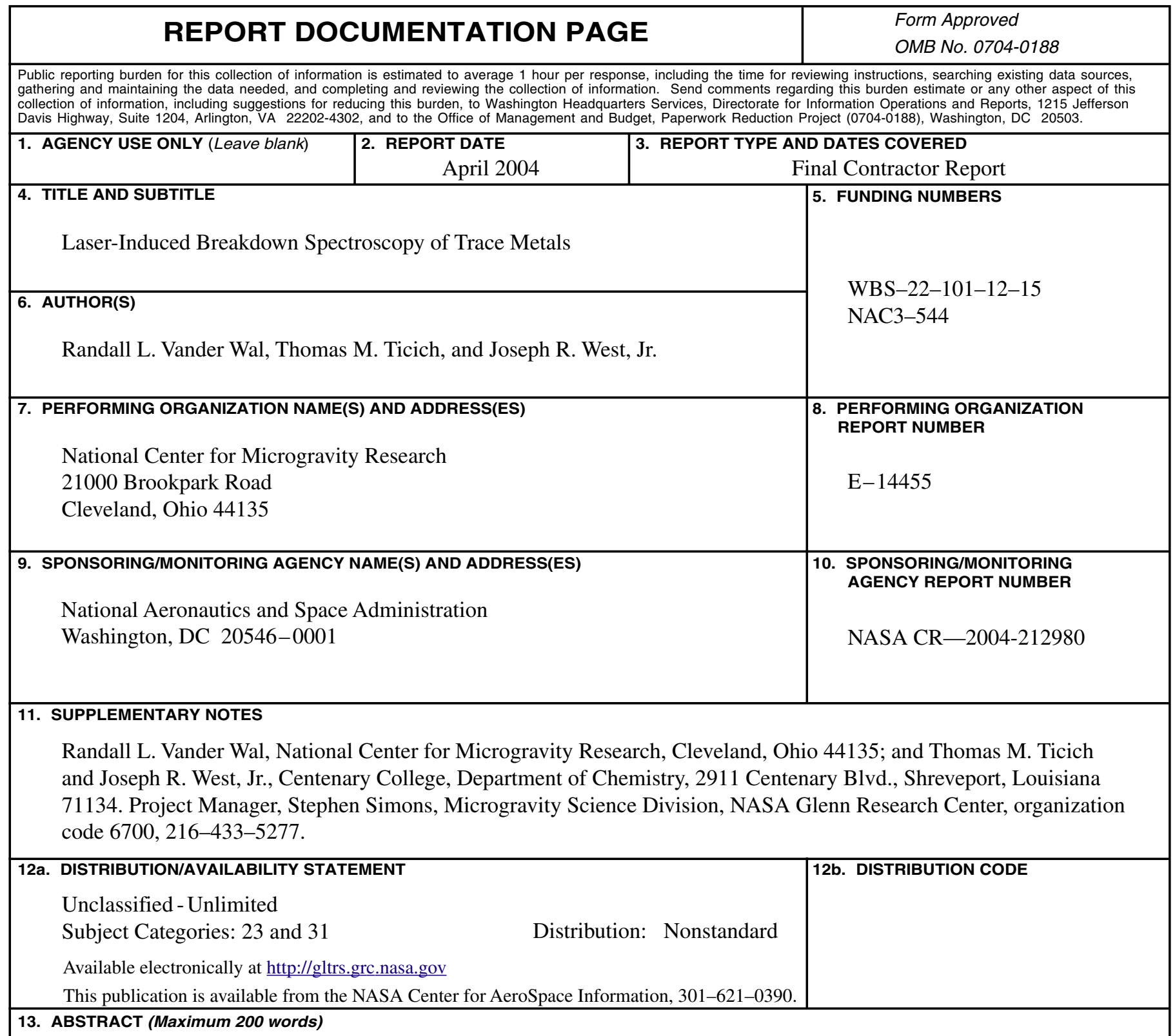

An alternative approach for laser-induced breakdown spectroscopy (LIBS) determination of trace metal determination in liquids is demonstrated. The limits of detection (LOD) for the technique ranged from $10 \mathrm{ppb}$ to $10 \mathrm{ppm}$ for 15 metals metals ( $\mathrm{Mg}, \mathrm{Al}, \mathrm{Si}, \mathrm{Ca}, \mathrm{Ti}, \mathrm{Cr}, \mathrm{Fe}, \mathrm{Co}, \mathrm{Ni}, \mathrm{Cu}, \mathrm{Zn}, \mathrm{As}, \mathrm{Cd}, \mathrm{Hg}, \mathrm{Pb}$ ) tested.

\begin{tabular}{|c|c|c|c|}
\hline 14. SUBJECT TERMS & & & 15. NUMBER OF PAGES \\
\hline LIBS; Environmental tra & metal analysis & & \begin{tabular}{|c}
13 \\
16. PRICE CODE
\end{tabular} \\
\hline $\begin{array}{l}\text { 17. SECURITY CLASSIFICATION } \\
\text { OF REPORT }\end{array}$ & $\begin{array}{l}\text { 18. SECURITY CLASSIFICATION } \\
\text { OF THIS PAGE }\end{array}$ & $\begin{array}{l}\text { 19. SECURITY CLASSIFICATION } \\
\text { OF ABSTRACT }\end{array}$ & 20. LIMITATION OF ABSTRACT \\
\hline Unclassified & Unclassified & Unclassified & \\
\hline
\end{tabular}



